\title{
El argot carcelario mexicano del siglo XIX en la literatura costumbrista: el caso de La Chaquira (Belén por dentro)
}

\author{
Ivo Buzek* \\ Universidad Masaryk, República Checa
}

\begin{abstract}
Resumen
El principal objetivo del artículo es el estudio léxico-semántico del argot carcelario mexicano a finales del siglo XIX, tal como se aprecia en el texto de la novela costumbrista La Chaquira (Belén por dentro) de Francisco García González, publicada por entregas en el periódico mexicano El Relámpago entre 1894 y 1895. Se prestará atención a su estructura (léxico patrimonial español, nahuatlismos, anglicismos, etc.) y a los principales procesos lexicogenéticos y de cambios de significado que allí se documentan. Otro punto de interés será su relación con otros argots carcelarios hispanos, sobre todo el peninsular, desde una perspectiva tanto diacrónica como sincrónica de aquel entonces para poder documentar las direcciones de la evolución de este sociolecto como propiamente mexicano o, si se quiere, "nacional".
\end{abstract}

Palabras clave: argot carcelario, lexicología histórica, formación de palabras, cambio de significado.

Para correspondencia, dirigirse a: Ivo Buzek (ibuzek@phil.muni.cz), Ústav románských jazyků a literatur, Masarykova univerzita, Filozofická fakulta, Arna Nováka 1, 60200 Brno, Česká republika. 


\title{
MEXICAN PRISON SLANG IN THE 19TH CENTURY LITERATURE OF MANNERS: THE CASE OF LA CHAQUIRA (BELÉN POR DENTRO)
}

\begin{abstract}
The main aim of the paper is to offer a lexicological and semantic study of the Mexican prison slang at the end of the 19th century that appears in the text of the novel of manners La Chaquira (Belén por dentro), by Francisco García González, published in instalments in a Mexican newspaper El Relámpago during 1894 and 1895. Attention will be paid to its structure (patrimonial vocabulary, Nahuatlisms, Anglicisms, etc.) and to principal word formation processes and patterns of semantic change that can be found there. Another aim of study will comprehend its comparison with other Hispanic prison slangs, mainly the Spanish one, from the historical point of view. This historically focused comparison and analysis will show directions of evolution that would allow us to interpret this jargon as properly Mexican, or "national".
\end{abstract}

Keywords: prison slang, historical lexicology, word formation, semantic change.

Recibido: 10/07/18 Aceptado: 10/01/19

\section{INTRODUCCIÓN ${ }^{1}$}

Mucho se ha hablado de las lagunas de conocimiento que en la historia de la lengua española presenta el siglo XIX, aunque es cierto que en los últimos años se ha avanzado bastante en la investigación y muchas dudas ya han sido aclaradas (Ramírez Luengo, ed., 2012; Zamorano, ed., 2012; Melis y Flores, eds., 2015; Buzek y Šinková, eds., 2015a y 2015b; o Carpi y García

1 Una primera versión de este trabajo fue presentada como comunicación en el VII Simposio Internacional de Hispanistas "Encuentros 2018" (24-26 de mayo de 2018, Universidad de Łódź, Polonia) bajo el título "De presidentes, golpes y otros criminales". Se inscribe dentro del proyecto Corpus diacrónico para el estudio de las actitudes lingüísticas en América y España en los siglos XVIII y XIX (FFI2016-76874-P), concedido por el Ministerio de Economía y Competitividad del Gobierno de España, y cuenta asimismo con el apoyo de la Facultad de Filosofía y Letras de la Universidad Masaryk. 
Jiménez, eds., 2017). No obstante, sigue habiendo áreas por explorar en todos los niveles de la lengua española en su complejidad geográfica y social.

El objetivo de estudio de este artículo es el léxico carcelario de México de finales del siglo XIX, época conocida en la historia del país como porfiriato. Es una continuación, o más bien un complemento, de un trabajo anterior (Buzek 2018) dedicado al argot carcelario mexicano recogido en una novela costumbrista de la época, La Chaquira (Belén por dentro), de Francisco García González (1894). En este nos hemos dedicado al argot recopilado en un glosario adjuntado, mientras que ahora nos vamos a centrar en los términos que aparecen directamente en el texto de la novela. Continuaremos aquí en la misma dirección que ya hemos emprendido en el estudio anterior y veremos si dichas unidades léxicas se han formado por mecanismos internos de la lengua española o si vienen de fuentes foráneas, y hasta qué punto han mantenido la relación de parentesco (ya relativamente lejano) con el argot de la delincuencia peninsular, tanto desde una perspectiva histórica como coetánea. Nuestro fin es, por tanto, ir recogiendo y colocando en su sitio piezas de un mosaico que cuando esté completo nos ayudará a reconstruir e interpretar adecuada y coherentemente la historia del léxico popular urbano y el argot de la delincuencia mexicanos. Estamos convencidos de que los sociolectos de las clases humildes y marginadas no deberían estar fuera de miras de los estudiosos y que deberían ser objetos de análisis como otros planos y registros de la lengua si queremos entender la historia y el presente del español mexicano en un contexto más amplio.

Si volvemos nuestra mirada al caso del léxico del español mexicano en un sentido más amplio, nos damos cuenta de que tradicionalmente los lexicólogos han prestado más atención a los indigenismos y al habla rural, por una parte, o al léxico del habla culta y de los usos elevados, por la otra (Lope Blanch 1965 y 1969; García Frazier 2006; o García Godoy 1998, entre otras posibles referencias). Sin embargo, como hemos apuntado antes (Buzek 2017 y 2018), se echan de menos estudios sobre el habla popular urbana y sus sociolectos en su dimensión histórica seguidos por una visión de conjunto adecuadamente interpretada (por ejemplo, según el marco metodológico formulado en Barriga Villanueva y Martín Butragueño 2010 y 2014); una labor que ya se ha hecho, en parte, para el español mexicano actual en su registro popular y en su ámbito urbano, o más bien capitalino (Lara 1992; Hernández Martínez 1999, 2002 o 2004), pero que en buena medida sigue por hacer, insistimos, en su dimensión histórica. 


\section{LA CHAQUIRA (BELÉN POR DENTRO): LOS RIESGOS Y LAS VENTAJAS DE UN TEXTO LITERARIO COMO CORPUS}

Como ya hemos adelantado, el presente estudio estará basado en una fuente literaria, la novela costumbrista La Chaquira (Belén por dentro), de Francisco García González, publicada por entregas en el periódico mexicano El Relámpago $^{2}$, entre 1894 y 1895 (en la portada se lee la fecha de publicación de 1894). La novela se desarrolla en general en los ámbitos populares y marginados mexicanos y la mayor parte del texto tiene la forma epistolar en la que los protagonistas, don Celso y Sofía, describen el ambiente de la cárcel de Belén, en la ciudad de México. Estamos convencidos de que la novela tiene un gran interés lexicológico, puesto que ofrece una buena muestra del argot carcelario de la época. Según nos consta, la novela nunca ha sido objeto de estudio ni de investigadores de la literatura mexicana ni de lingüistas, pero su valor documental no les ha pasado desapercibido a los historiadores (Garza 2007).

Sin embargo, esto no quiere decir que aceptemos sin actitud crítica todo lo que hallamos entre sus páginas. Estamos trabajando con un texto literario y somos conscientes de que las formas y maneras de hablar de sus personajes pueden fomentar estereotipos y tópicos cuando esos representan unos "tipos sociales" cuyas actuaciones idiomáticas sirven ante todo para caracterizarlos como tales, puesto que, como afirma Oesterreicher (2004: 734), "lo específico del texto literario consiste exactamente en la posibilidad de fingir [...] todas las formas de este continuo concepcional".

Ahora bien, las palabras de Oesterreicher se refieren sobre todo a los pasajes dialogados, no obstante, la mayoría de los términos carcelarios presentes en la novela aparece en los pasajes expositivos, sobre todo en los capítulos en forma epistolar presentados como testimonios de la realidad de la cárcel. También hay que constatar que los textos literarios que retratan los bajos fondos de las sociedades hispanohablantes tradicionalmente han sido utilizados como material de estudio casi exclusivo y la mayoría de los investigadores ha sido consciente de sus riesgos. Para la germanía española áurea, contamos, por ejemplo, con excelentes trabajos de Alonso Hernández (1979 o 1990), para los estudios lingüísticos de los bajos

2 Accesible a través de la Hemeroteca Nacional Digital de México, disponible en http:// www.hndm.unam.mx/consulta/resultados/visualizar/558075be7d1e63c9fea1a400?resultado $=12 \&$ tipo $=$ publicacion\&intPagina $=0$ [Consulta: $28 / 1 / 2018]$. 
fondos de la sociedad mexicana a finales de la época colonial y durante la independencia contamos con los trabajos de Davis (1956) o Trejo (1961), pero como ya hemos mencionado, los estudios históricamente orientados sobre los sociolectos marginales en ambos lados del Atlántico no abundan y no permiten sacar unas conclusiones de síntesis. Dicho sea de paso que investigaciones históricas sobre hablas marginales basadas en documentos no literarios (actas de juzgado, etc.) están por hacerse.

En lo que atañe al texto de La Chaquira, encontramos entre sus páginas dos grupos de términos argóticos que están hasta cierto punto separados y por ello hemos decidido dedicarles dos trabajos independientes, como ya hemos apuntado. Por una parte, tenemos un grupo de 52 voces que aparecen esparcidas en el texto de la novela -aunque es cierto que la mayoría se encuentra en los pasajes epistolares ambientados en la cárcel-; otro grupo lo forma un "Vocabulario de argot ó jerga" que contiene 115 términos y figura como apéndice de una de las cartas de don Celso a Cecilia, la madre de Sofía, y que ya hemos analizado antes (Buzek 2018).

Las voces argóticas del texto de la novela coinciden con las recogidas en el "Vocabulario" mucho menos de lo que cabría esperar -y esta ha sido también una de las razones por la que hemos decidido dedicarles dos estudios separados-. De los 115 términos del "Vocabulario" solo 19 aparecen también en el texto de la novela. Son las siguientes: brisa 'carne'; frajo 'cigarrillo'; gamuza 'pan'; grande 'peso (moneda)'; lima 'camisa'; manrro [marro] 'pan'; mula 'homosexual'; nagual 'ladrón'; pantofacia 'comida'; papel 'billete (dinero)'; parral 'frijol'; salir a patinar [patinar] 'barrer espacios públicos fuera de la cárcel'; pitoche 'seis centavos'; sura 'peseta'; tecolote 1 [tecolote 2] 'cierta fase del juego de La Caja'; tonedo 'atole'; toro 'carne'; tostador 'cincuenta centavos'; tuje 'sarape'. Además, en algunos casos la forma y el significado varían:

- manrro "pan' se recoge en el "Vocabulario" como marro; podría tratarse, en principio, de una errata, pero ambas formas se documentan asimismo en los inventarios del argot mexicano que estamos manejando, sin embargo, manrro es la forma que se documenta con más frecuencia;

- salir a patinar 'barrer espacios públicos fuera de la cárcel'; en el "Vocabulario" está documentado como patinar y con un significado distinto, 'barrer por castigo' (y seguramente en el interior de la cárcel);

- tecolote 1 'cierta fase del juego de La Caja'; en el "Vocabulario" viene con el significado 'gendarme', que a su vez está bien documentado en las fuentes lexicográficas. 
En nuestro estudio anterior (Buzek 2018) hemos formulado la hipótesis de que, sin embargo, a falta de pruebas es de momento solo una especulación. Nos da la impresión de que García González había manejado un listado de términos argóticos y como no los utilizó todos en el cuerpo de la novela, decidió incluir el resto como "Vocabulario" adjuntado en una de las misivas. Sigue siendo una incógnita cómo había recopilado el léxico, si había sido de su propia cosecha o si había sido recopilado por otros. No obstante, parece que el léxico era conocido y accesible también a otros porque una parte de él (una veintena de términos coincidiendo tanto en la forma de las voces argóticas como en sus equivalentes) fue incluida también en el primer diccionario de mexicanismos que, además, era coetáneo de la novela, el Diccionario de mejicanismos, de Féliz Ramos i Duarte (1895)³.

A continuación vamos a proceder ya sin más demora al análisis y comentario de las 52 voces del argot carcelario presentes en el texto de la novela. En primer lugar, nos vamos a fijar si tienen continuidad con el argot carcelario español. En segundo lugar, estudiaremos su evolución externa, es decir, si son préstamos de lenguas con las que el español (mexicano) ha estado en contacto y, en tercer lugar, nos ocuparemos de su evolución interna, es decir, si se han formado según los procedimientos habituales de la neología formal y neología semántica de la lengua española, con especial atención a los mecanismos de la formación de las hablas marginales. Al final prestaremos atención a las áreas temáticas a las que pertenecen las voces en cuestión.

\section{LA ESTRUCTURA DEL ARGOT CARCELARIO EN EL TEXTO DE LA NOVELA}

Antes de empezar la tarea del análisis y comentario, habría que concretar qué procedimientos y medidas hemos tomado para identificar las voces que serán nuestro objeto de estudio como propias del argot carcelario o de la delincuencia. En varios casos, las palabras son expresamente identificadas así en el texto, como en los ejemplos de basurero, carro fúnebre, bicicleta y nagual:

\footnotetext{
3 Para el diccionario de Ramos i Duarte, véanse Buzek (2015), y Buzek y Gazdíková (2017).
} 
1. Basureros, como lo indica la palabra, son los presos que recogen y votan [sic] la basura. $(176)^{4}$

2. Al vagón que los conduce á los jurados, le nombran "carro fúnebre", y á los cajones de basura les dicen "bicicletas". (126)

3. Todos los que allí duermen tienen que cuidarse, admírate, de los rateros, que se les designa con el nombre de naguales, y á los que, como ya son conocidos, se les coloca en un sitio apartado. (204)

En muchas ocasiones son también procedimientos tipográficos, como las cursivas, que nos ayudan a identificar los términos, como en los siguientes casos:

4. A las once de la mañana un trozo de carne, toro ó $\underline{\text { brisa }}$, una bombilla de arroz aguado, ó granito, y una gamuza ó manrro. (127)

No obstante, en otros casos, aunque son muy contados, es el contexto que nos dice que se trata de términos relacionados con el ambiente carcelario. Curiosamente, suelen ser casos del léxico administrativo del ámbito presidiario, que probablemente eran de conocimiento más general y que no habrán sido exclusivos de los reclusos, como en los siguientes ejemplos de calificación y calificado:

5. Cuando concluye la calificación, un empleado caracterizado de la cárcel pasa á la galera, donde permanecen todos los calificados en perfecto orden, y al grito "firmes" dado por un golpe, se descubren todos y dicho empleado les va notificando uno á á [sic] uno su sentencia. (116-117)

En casos como este son imprescindibles explicaciones contextualizadas, como la que ofrece el diccionario de García Icazbalceta (1899), reproducida a su vez en el de Santamaría 2000 [1959]:

Calificación. f. Llámase así en México a cierta distribución (no sé si legal) que acostumbra hacer cada noche el Gobernador del Distrito Federal, o su secretario, de los reos de delitos no graves o de infracciones de policía, que han sido aprehendidos en el día, y a su arbitrio suelta a unos, impone a otros ciertas penas y envía al resto a la cárcel, consignados al juez de turno.

4 Mantenemos la ortografía tal como aparece en la novela. 
Para obtener estas "explicaciones contextualizadas" nos hemos visto obligados a acudir a una amplia gama de fuentes lexicográficas. Para el léxico que el argot carcelario mexicano de la época compartía con el argot español hemos acudido a los repertorios de la germanía áurea (Chamorro 2002; Hernández Alonso y Sanz Alonso 2002) y al estudio de Salillas que a su vez contiene dos vocabularios: "El vocabulario de germanía" (Salillas 1/1896) y el "Vocabulario del caló jergal" (Salillas 2/1896).

En lo que se refiere al léxico que según el contexto debería ser propio del español mexicano, hemos consultado los diccionarios de mexicanismos publicados en la misma época o posteriores pero basados sobre documentación datada en fechas relativamente cercanas (Ramos i Duarte 1895; García Icazbalceta 1899; Santamaría 2000 [1959]), y los actuales, generales y de americanismos o mexicanismos, cuya sincronía es relativa y se expande considerablemente al pasado (DLE; DA; Company 2010). Asimismo, hemos acudido a los diccionarios de la delincuencia mexicana, aunque es cierto que son posteriores y que entre estos y la novela hay con frecuencia unos 50 años o más de diferencia (Aguilar 1941; Amor 2014 [1947]; Chabat 1964; Colín 1997 [1987]; Franco 2014 [194?]).

\subsection{LA FILIACIÓN HISTÓRICA CON EL ARGOT ESPAÑOL}

En primer lugar tenemos que advertir que hemos contrastado el argot mexicano con el español peninsular en gran medida porque existen estudios relativamente detallados sobre la historia de argot español peninsular, pero no existen semejantes estudios sobre las historias de las hablas marginales en las variedades latinoamericanas.

En el texto de la novela hemos encontrado pocas voces que coincidan total o parcialmente con las documentadas en el argot español (áureo o coetáneo), pero si tomáramos en consideración también las recogidas en el "Vocabulario", podríamos vislumbrar algunas señas de parentesco lejano con el argot español.

Son solo tres las voces que muestran cierta continuidad con la germanía española áurea (tanto desde el punto de vista formal como del significado: cachucha 'preso distinguido' [¿de cachucho 'oro'?]); hacer viaje 'llevar objetos robados de un lugar a otro' [¿de hacer un viaje 'robar'?]; y *lima

\footnotetext{
5 Marcamos con un asterisco voces que aparecen tanto en el "Vocabulario" como en el texto de la novela.
} 
'camisa' que a su vez parece que continuaba también en el argot español de finales del XIX, puesto que se documentaba asimismo en el estudio de Salillas (1896). Otra voz en común con el argot español coetáneo sería el gitanismo manrro 'pan' [*marro].

6. Uno de los cuartos está destinado para que se bañen los presos distinguidos, y el otro para el resto de la prisión, motivo por el cual han bautizado al primero con el nombre de "Baño de los cachuchas", y al otro con el de "Baño de los chilapeños". (148)

[Chamorro 2002, Hernández Alonso y Sanz Alonso 2001, y Salillas 1/1896: cachucho 'oro', sería una metáfora con intención irónica; no vemos relación con cachucha 'Copa que se toma compuesta de varios vinos o licores' (Santamaría 2000 [1959]); ni con 'Especie de gorra' (DLE); ' $M x, G u, H o, E S, N i, R D, C o, V e, B o$. Gorra de tela con visera' $(D A)$; 'Prenda de vestir, generalmente de tela y con visera, con que se cubre la cabeza' $(D E M)]$

7. [...] pero Pablo, tomándola por los brazos, la ayudó á descender, quedándose arriba Amada sola, pues Pedro se ocupaba en hacer viajes, llevándose los efectos robados á la vivienda. (93)

No había pasado mucho tiempo que Pedro se había reunido con Amada, después de haber hecho su último viaje, cuando se oyeron dos gritos de mujer, casi simultáneos, y á pocos momentos una detonación de arma de fuego. (93)

[Chamorro 2002: hacer un viaje 'robar']

8. Cuando los presos no tenían dinero, el coime prestaba por una camisa, ó lima, una peseta ó sura; por un zarape, ó tuje, en buen estado, un tostón, ó tostador: y si era enteramente nuevo, un grande, y todo á fuerza de súplicas, resultando, que á las dos ó tres de la mañana y á veces hasta el amanecer, que se levantaba el juego, se encontraba el coime rodeado de un montón de ropa y de una porción de hombres enteramente encuerados. (210)

[Chamorro 2002, Hernández Alonso y Sanz Alonso 2002: 'La camisa'; Salillas 1896: 'Camisa', en ambos vocabularios]

9. En la mañana á las seis en verano, y á las siete en invierno, una bombilla de atole ó tonedo, y un pambaso, que llaman gamuza ó manrro. (127)

[Amor 2014 [1947]: Pan 'Marro'; Aguilar 1941: 'Pan' y Manrro 'Comida'; Chabat 1964: 'Pan' y Manrro 'Comida. Pieza de pan en la prisión'; Colín 1997 [1987]: 'Pan, bolillo’; cf. Salillas 2/1896: Manró. [etim. sanscr.] 'Pan'] 


\subsection{CONTINUIDAD CON EL ESPAÑOL MEXICANO GENERAL Y ADAPTACIONES DE OTROS SOCIOLECTOS}

Otro grupo de palabras está formado por términos del español mexicano general que en la cárcel han sufrido una adaptación semántica, o más bien una acomodación pragmática y situacional al ámbito presidiario. Puede que no haga falta incluirlas, pero como están marcadas en el texto como propias del argot y como de momento no tenemos más información sobre el contexto, hemos decidido añadirlas. Por ejemplo, barrendero 'Persona encargada de barrer la basura de las calles u otros lugares públicos' (DEM) y basurero 'Empleado del servicio público encargado de recoger la basura; señor de la basura' (DEM), literalmente hacían los mismos servicios, pero en la cárcel y de momento no sabemos si fue un castigo o un privilegio, si conllevaba unas ventajas o no, etc. Aparte de basurero y barrendero, otras voces de similar índole serían boquete, gratificación y ranchero.

10. Barrenderos. Los presos que barren los distintos departamentos de la Prisión. (176)

[DEM: 'Persona encargada de barrer la basura de las calles u otros lugares públicos']

11. Basureros, como lo indica la palabra, son los presos que recogen y votan [sic] la basura. (176)

[DEM: 'Empleado del servicio público encargado de recoger la basura; señor de la basura']

12. El atole, el arroz y los frijoles en barriles, que tienen en la boca unas grandes azas [sic] de hierro, por las que se atraviesa un palo, que cargan en los hombros dos presos, á quienes se les llama rancheros; [...]. (128)

Rancheros se llaman los presos que tienen el trabajo exclusivo de cargar los barriles y cajones de la caridad y procurar el aseo de ellos. (176)

[Franco 2014 [194?]: 'persona que guisa el rancho a quien lo reparte [sic]'; Colín 1997 [1987]: 'Rancheros. Cocineros de los reclusorios o establecimientos penitenciarios'; $c$ f. rancho 'comida penitenciaria (Aguilar 1941 y Amor 2014 [1947]) y 'comida que dan en la cárcel' (Chabat 1964)]

13. A fuerza de súplicas y también de gratificaciones, que son aquí la palanca de Arquímedes, he logrado establecer mi correspondencia con mi idolatrada Sofía, que se encuentra en su departamento. (171) [DEM: 'Recompensa o retribución, generalmente monetaria, que se da por un servicio o un favor recibido'] 
14. En la parte baja y pasada la escalera, está una puerta maciza que comunica á un pequeño departamento llamado el boquete, que se compone de tres piezas: la primera que tiene ocho varas de largo por cinco de ancho, que es el lugar adonde se depositan las canastas de comida y otoos [sic] objetos destinados á los presos de distinción; [...] (166)

Por este "boquete" se admiten y envían comidas, bultos de ropa, muebles, maderas y toda clase de objetos y materiales para los trabajos de los presos, que son conducidos en hombros ó en parihuelas al interior de la Cárcel, por galeros, bajo la vigilancia de varios Presidentes. (167)

[DLE: 'Entrada estrecha de un lugar'; $c f$. también boquetero, no documentado en la novela, Santamaría 2000 [1959]: 'Empleado de las cárceles que, colocado en el primer postigo o boquete, registra a los presos que llegan y los introduce al edificio' (s/v boquetero), 'En el lenguaje carcelario, guardián de celda, en la prisión, así como el $\underline{\text { boquetero }}$ es guardián de puerta' ( $\mathrm{s} / \mathrm{v}$ galero)]

Los siguientes términos pertenecen en principio al léxico administrativo, pero como a su vez hacen referencia a los presos y a la realidad de la cárcel, con mucha probabilidad habrán sido comunes de ambas áreas. Son las voces calificación, calificado, calificar y partida:

15. Cuando concluye la calificación, un empleado caracterizado de la cárcel pasa á la galera, donde permanecen todos los calificados en perfecto orden, y al grito "firmes" dado por un golpe, se descubren todos y dicho empleado les va notificando uno á á [sic] uno su sentencia. (116-117)

[García Icazbalceta 1899 y Santamaría 2000 [1959]: 'Llámase así en México a cierta distribución (no sé si legal) que acostumbra hacer cada noche el Gobernador del Distrito Federal, o su secretario, de los reos de delitos no graves o de infracciones de policía, que han sido aprehendidos en el día, y a su arbitrio suelta a unos, impone a otros ciertas penas y envía al resto a la cárcel, consignados al juez de turno'; la voz calificado 'preso provisional y arbitrariamente sentenciado' no cuenta con documentación lexicográfica]

16. Los consignados al turno pasan al día siguiente, muy temprano, á la Cárcel Nacional, y á los otros se les califica como se ha dicho antes. (125)

[Santamaría 2000 [1959]: 'Hacer la autoridad administrativa la clasificación de los detenidos, consignando a unos a las autoridades judiciales y sentenciando a otros'] 
Y finalmente encontramos en la novela dos términos originarios del léxico militar lo que se explicaría por el carácter jerarquizado de las categorías entre los presidiarios: cabo y mayor.

17. Cabos. Son poco más ó menos que los anteriores [presidentes] y así se les llama en el Departamento de Detenidos. (177)

[DEM: 'Grado militar inferior al de sargento y superior al de soldado raso o al de marinero']

18. El departamento tiene un Mayor, que es un preso de comisión, bajo cuya responsabilidad está el orden, limpieza y arreglo de todas las dependencias, teniendo como $2^{\circ}$ á otro, que se intitula: "Cabo de Bomberos," así como ocho cabos que lo auxilian en sus trabajos. (124-125)

Mayores. Se llaman los presos que son Jefes de cada Departamento, á cuya voz, secundada por sus Presidentes, se mueve toda la masa de hombres con la precisión y regularidad de un Ejército perfectamente disciplinado. (176)

[DLE: '9. desus Caudillo, capitán, jefe de guerra. Se usa todavía en algunos ejércitos como denominación de empleo equivalente al de comandante'; DEM: '4. (Mil.) Grado militar inferior al de teniente coronel y superior al de capitán primero'; $c f$. el significado documentado en la germanía: Chamorro 2002 'Jefe de los ladrones y las putas', o el guatemalteco, relacionado con la policía: $D A$ : ' $G u$. Auxiliar de policía que trabaja en un municipio']

\subsection{EVOLUCIÓN EXTERNA}

El contacto con otras lenguas no se nota mucho en la estructura del léxico aquí estudiado. Hemos identificado tres préstamos del gitano-español, *brisa; *frajo; *manrro [marro], y dos del náhuatl, *nagual y *tecolote 1. Los gitanismos probablemente serán en realidad españolismos y habrán pasado al argot mexicano del argot de la delincuencia española, ya que la inmigración de los gitanos a México fue posterior, de mediados del siglo XX, y estaba formada más bien por grupos procedentes de los Balcanes (Adamou 2013). La presencia ocasional de los nahuatlismos tampoco es sorprendente. Como hemos averiguado en nuestros estudios anteriores (Buzek 2014 y 2017), el argot de la delincuencia siempre ha sido urbano y, por tanto, se ha nutrido en su mayoría a base de procedimientos internos. 
19. A las once de la mañana un trozo de carne, toro ó $\underline{\text { brisa }}$, una bombilla de arroz aguado, ó granito, y una gamuza ó manrro. (127) [Ramos i Duarte 1895: 'Carne de res'; Santamaría 2000 [1959]: 'En caló mejicano, carne de res, que a veces se dice también brinza. -(Una y otra acepciones son translaticias de la que en el caló castellano tiene brinza, de la cual se formó sin duda BRISA)'; Aguilar 1941: 'Brizna.Pieza de carne que se da en la prisión, ración'; Chabat 1964: 'Brizna: Pedazo de carne. Ración de carne que se da en la cárcel']

20. En la cárcel, lo mismo que en todas partes, pero aquí con más preferencia, el dinero es el all mighty dollar, pues no falta á quien repartirlo para conquistar las cosas prohibidas, con la única diferencia de que se tiene en consideración la categoría del que se gratifica, dando desde un frajo hasta un grande, y á veces un papel. (194)

[Aguilar 1941: 'Cigarrillo de tabaco'y 'Cigarro'; Amor 2014 [1947]: 'Cigarro de tabaco'; Chabat 1964 y Colín 1997 [1987]: 'Cigarrillo'; $D A$ : 'Gu, ES. Cigarrillo']

21. En la mañana á las seis en verano, y á las siete en invierno, una bombilla de atole ó tonedo, y un pambaso, que llaman gamuza ó manrro. (127)

[Aguilar 1941: 'Pan' y 'Comida'; Amor 2014 [1947]: 'Comida. Marro'; Chabat 1964: 'Pan' y 'Comida. Pieza de pan en la prisión'; Colín 1997 [1987]: 'Pan, bolillo'; cf. Salillas 2/1896: 'Manró. Pan']

22. Todos los que allí duermen tienen que cuidarse, admírate, de los rateros, que se les designa con el nombre de naguales, y á los que, como ya son conocidos, se les coloca en un sitio apartado. (204) [Franco 2014 [194?]: 'Ladrón habitual'; Chabat 1964: 'El que usa zapatos tennis o de suela blanda para entrar a robar'; Colín 1997 [1987]: 'Tonto, "indio", ladrón que roba en casas habitación en ausencia de sus moradores'; $c f$. nagualear 'Robar' (Santamaría 2000 [1959]) y 'Robar a los dormidos' (Amor 2014 [1947])]

23. Se sentaba entre una rueda de hombres un preso, que se intitulaba el coime, provisto de un naipe y de diez ó veinte pesos en moneda menuda; echaba el albur, y si la apuesta la perdía el monte, el punto pagaba un real por un peso; por un tostón medio, etc., etc., entendiéndose que esa contribución era, no sólo por albur seco, sino en cada una de las diversas fases que dicho juego tiene, como viejo, camonina, tecolote, chiquito, etc., etc. (210)

[Santamaría 2000 [1959]: 'Cierto lance en el juego de albures'] 


\subsection{EVOLUCIÓN INTERNA}

En el siguiente apartado nos vamos a dedicar a las voces formadas sobre bases patrimoniales dentro del ámbito del argot mexicano según los patrones de la neología semántica habituales en el argot -no hemos encontrado en la novela voces formadas por la neología formal que se puedan identificar como formaciones exclusivamente argóticas- siguiendo muy de cerca a los autores que se han ocupado de los procesos de la formación en las hablas marginales hispánicas en varias fases de su historia y del alcance geográfico (Alonso Hernández 1979 para la germanía áurea; Sanmartín 1998 y 2006 para el argot español peninsular; y Martínez, Vila Rubio, Castañeda y Henao 2012 para el estudio contrastivo entre el argot español y el parlache colombiano). Aparte de las modalidades del cambio semántico, muy bien representadas también en la muestra que estamos estudiando aquí, prestaremos atención a las unidades fraseológicas, sobre todo a las locuciones nominales.

\subsubsection{Transformaciones semánticas}

No ha sido ninguna sorpresa que las transformaciones semánticas forman el grupo más numeroso de nuestro pequeño corpus. Son 23 en total y de ellas tres se clasificarían como metonimias, mientras que metáforas serían 20. En todos los casos se trata de términos motivados y muy marcados. Como advierte Sanmartín (1998: 80-81), en su formación es necesario prestar atención a las causas psicológicas, a la emotividad, a la intensificación y a la expresividad. No obstante, apunta a su vez la investigadora valenciana, frecuentemente la motivación no está del todo clara, "puesto que en muchos casos no sólo la metáfora se basa en otras metáforas anteriores, sino que crea la propia semejanza" (Ibid.).

En primer lugar, dirigiremos la mirada hacia metonimias, productos de sustitución de nombre de una cosa por uno de sus atributos. Son solo 3, como ya hemos dicho: chilapeño 'persona ordinaria' (de sombrero de paja tradicionalmente fabricado en Chilapa de Álvarez, municipio del estado de Guerrero'); cumplido 'preso que ha cumplido su condena'; y *parral 'frijol' (de Parral, municipio de Chihuahua, famoso por producción de un tipo de frijol).

24. La viveza de alejar del Departamento a los presos en los momentos del reparto, es muy conocida; se les manda fuera del Edificio á la limpieza, al Hospital, á práctica, etc., ó se echa á los cumplidos, esto es, á los que les toca salir en libertad, [...]. (175)

[Sin documentación lexicográfica] 
25. Uno de los cuartos está destinado para que se bañen los presos distinguidos, y el otro para el resto de la prisión, motivo por el cual han bautizado al primero con el nombre de "Baño de los cachuchas", y al otro con el de "Baño de los chilapeños". (148)

[Ramos i Duarte 1895: 'Sombrero de paja ordinario. Tomó el nombre del lugar donde los hacen, que es en el pueblo de Chilapa'; Santamaría 2000 [1959]: 'Chilapaneco, y aún más usado que éste'; s/v chilapaneco. 'Oriundo, natural o habitante de Chilapa, población de Guerrero. 2. Lo relativo a este lugar y a otros muchos del país que llevan el mismo nombre'; $D A$ : 'Sombrero de paja que tradicionalmente se fabrica en Chilapa de Álvarez, municipio del estado de Guerrero']

26. A las cuatro de la tarde una bombilla de frijoles ó parrales, y la gamuza. (127)

[Aguilar 1941: parrales 'frijoles'; Amor 2014 [1947]: frijoles 'parrales, parraleños; Chabat 1964: parrales 'frijoles' y parraleños 'frijoles'; Colín 1997 [1987]: parrales 'frijoles'; cf. Ramos i Duarte 1895: parralanda 'comida'; y sobre todo Santamaría 2000 [1959]: parraleño, ña '[...] hay un frijol especial, rayado de rojizo y amarillo, llamado frijol parraleño, muy estimado en comercio, en Méjico']

Como es habitual en estudios como el nuestro, entendemos las metáforas como transposiciones basadas en similitud de aspectos, de usos y de funciones. Seguiremos aquí de nuevo a Sanmartín (1998) que en su estudio del argot español identifica diversos tipos de metáforas con estructura interna, de acuerdo con los postulados clásicos de Lakoff y Johnson (1980).

En primer lugar, estarían las metáforas estructurales, es decir, cuando un concepto se organiza metafóricamente con términos de otro. El vehículo de la metáfora puede ser un objeto (bicicleta 'cajón de basura'; cachucha 'preso distinguido'; carro fúnebre 'vagón que conduce a los detenidos al jurado'; galero 'guardián de celda'; golpe 'preso que repite las órdenes dadas'; granito 'arroz aguado'; *papel 'billete'; pito 'cabo de limpieza'); o un animal (gatero 'preso que sirve a otro'; *mula 'preso homosexual'; *toro 'ración de carne').

Otro tipo estaría comprendido por las metáforas ontológicas, en las que consideramos acontecimientos, actividades, emociones, ideas, etc., como entidades y sustancias (cabo de bomberos 'preso responsable por la limpieza'; caridad 'comida de la cárcel'; destino 'sentencia por cumplir'; *grande 'peso (moneda)'; salir a patinar 'barrer $<$ los presos $>$ los paseos públicos o hacer otros trabajos fuera de la cárcel'; pito mayor 'preso responsable por recibir y distribuir comida en la cárcel'; pito segundo 'cabo 
de limpieza'; presidente 'preso guardián, responsable por un grupo de otros presos'; presidente de golpes 'preso que dirige a los golpes'; ser muy hombre 'ser fuerte y valiente').

Por último, estarían las metáforas orientacionales, que tienen poca rentabilidad en el argot (Sanmartín 1998: 88) y, por tanto, no sorprende que faltan también en nuestro grupo.

27. Al vagón que los conduce á los jurados, le nombran "carro fúnebre", y á los cajones de basura les dicen "bicicletas." (126)

[Ambas sin documentación lexicográfica]

28. Por este "boquete" se admiten y envían comidas, bultos de ropa, muebles, maderas y toda clase de objetos y materiales para los trabajos de los presos, que son conducidos en hombros ó en parihuelas al interior de la Cárcel, por galeros, bajo la vigilancia de varios Presidentes. (167)

[Santamaría 2000 [1959]: 'En el lenguaje carcelario, guardián de celda, en la prisión, así como el boquetero es guardián de puerta'; cf. García Icazbalceta 1899 y Santamaría 2000 [1959]: 'Galerón. Galera ó sala grande que suele servir de cárcel'; $c f$. Franco 2014 [194?]: 'Galera. En una cárcel, sala ocupada por reclusos. Derivado de la pena de servir remando en las galeras reales, que se imponía a ciertos delincuentes. Echar a galeras. Condenar a galeras']

29. En estas cartas se hace un pintura á lo vivo, no sólo del lugar y de sus costumbres, sino de los usos, disposiciones oficiales, vida y trabajo de los presos, lenguaje que entre ellos se acostumbra, dando á la vez una idea de cómo están divididos sus departamentos, su régimen y carácter de sus empleados, desde la elevada personalidad del alcaide, hasta el celador, Mayor, Presidente y el humilde y despreciado golpe. (105)

Golpes se les llama aquí á unos presos apostados en las puertas ó de trecho en trecho para que repitan las órdenes ó llamamientos que se hacen, que en el Departamento de detenidos se gritan y en los demás se cantan.

[García Icazbalceta 1899 y Santamaría 2000 [1959]: 'Damos igual nombre a portero de golpe, que es "el que en la cárcel cuida de una segunda puerta, que suele tener pestillo de ruido para notar cuando se mueve" (Dicc.)']

30. A las once de la mañana un trozo de carne, toro ó brisa, una bombilla de arroz aguado, ó granito, y una gamuza ó manrro. (127)

[Sin documentación lexicográfica] 
31. En la cárcel, lo mismo que en todas partes, pero aquí con más preferencia, el dinero es el all mighty dollar, pues no falta á quien repartirlo para conquistar las cosas prohibidas, con la única diferencia de que se tiene en consideración la categoría del que se gratifica, dando desde un frajo hasta un grande, y á veces un papel. (194) [cf. Salillas 2/1896: Papil y Papiro 'Billete de banco'; DLE: papel 'Documento que contiene la obligación del pago de una cantidad, como una libranza, un billete de banco, un pagaré, etc. 1000 dólares en metálico y 100 en papel']

32. Los sentenciados á arresto menor, que son detenidos de uno á treinta días, suman, por término medio, unos sesenta hombres, los cuales duermen en el patio, bajo los arcos, vigilados por dos pitos, que así se llaman los cabos de limpieza. (139)

[Sin documentación lexicográfica]

33. Gateros á los presos que sirven como de domésticos á los otros presos, con algún cargo ó de cierta categoría, y entre esos galeros se ven muchos de corbata y levitilla soplando la lumbre con la resignación de un mártir. (176)

[cf. Ramos i Duarte 1895: 'Gato. Mozo de servicio, sirviente'; Chabat 1964: 'Gato. Criado. Sirviente. Empleado de baja categoría.' y 'Gata. Sirvienta. Doméstica. Criada.'; Colín 1997 [1987]: 'Gata. Sirvienta'; cf. también DEM: 'Gatero. adj y s m (Popular) 'Que enamora sirvientas']

34. Mulas. Se conoce con este nombre á los presos afeminados, que generalmente están encerrados en Bartolinas. Se peinan de onditas, andan muy planchados, muy bien calzados y perfumados, conociéndoseles por nombres que llaman la atención, como "La Camelia," "La Princes," "Los Caracoles," etc. etc. (177)

[Aguilar 1941 y Chabat 1964: 'Pederasta pasivo'; Colín 1997 [1987]: 'Mula (ser una) Perverso, malo, ingrato, no confiable, homosexual pasivo, hombre impotente']

35. A las once de la mañana un trozo de carne, toro ó brisa, una bombilla de arroz aguado, ó granito, y una gamuza ó manrro. (127)

[Sin documentación lexicográfica]

36. El departamento tiene un Mayor, que es un preso de comisión, bajo cuya responsabilidad está el orden, limpieza y arreglo de todas las dependencias, teniendo como $2^{\circ}$ á otro, que se intitula: "Cabo de Bomberos," así como ocho cabos que lo auxilian en sus trabajos. (124-125)

[Sin documentación lexicográfica] 
37. A estos alimentos les llaman los presos pantofacia, y el establecimiento caridad, (y este nombre está bien puesto, porque no se gana por el trabajo), [...]. (127-128)

[García Icazbalceta 1899 y Santamaría 2000 [1959]: 'Dase todavía este nombre a la comida que se ministra en las cárceles a los presos, porque antiguamente no se les daba ninguna, y había personas caritativas que andaban pidiendo limosna para el sustento de los encarcelados desvalidos que no tenían familia o amigos que los socorriesen. Pero hasta hoy se tiene por muy desdichado al pobre preso que no cuenta con más alimento que la comida oficial, es decir, la CARIDAD, que ya no lo es']

38. Para llamar á un preso que se va en libertad, la tonada difiere según los años que el sentenciado tiene que estar en la Cárcel, lo mismo que cuando se le llama para su destino, que es generalmente la Fortaleza de San Juan de Ulúa, porque entonces el canto es muy prolongado y muy triste. (176)

[Sin documentación lexicográfica]

39. Suele jugarse lotería de cartones, que á veces se les permite, y el preso que hace el gasto y aparece como empresario, saca buen provecho, pues suponiendo que se rife un tostón ó tostador, se reparten cincuenta cartones, de á centavo cada uno, y el agraciado paga á aquél cinco centavos de contribución; jugándose, por consiguiente, cincuenta loterías en una noche, cosa muy fácil, atendiendo al poco tiempo que dura cada juego y á lo temprano que se encierra á la gente, el empresario sacaría un diario de dos pesos cincuenta centavos, cantidad que se duplicaría si se rifara un grande, á dos centavos cartón. (209)

[Aguilar 1941 y Chabat 1964: Un grande 'Un peso'; Colín 1997 [1987]: Grande (Un) 'Billete de mil pesos']

40. Únicamente á los sentenciados á tres días, se les señala servicio de camilleros, basureros, etc., y á los de 6 á 15 días, se les manda barrer los paseos públicos ó á otros trabajos exteriores. A este servicio le llaman los presos "salir á patinar." (125)

[Sin documentación lexicográfica]

41. Pito Mayor. Es el preso que está encargado de recibir la caridad en el Departamento de Mujeres y distribuirlo en los otros de la Cárcel. (177)

[Sin documentación lexicográfica]

42. Pitos segundos se les llama aquí á los cabos de la limpieza. (176) [Sin documentación lexicográfica] 
43. Presidentes. Son los ayudantes, digámoslo así, de los Mayores, gentes que generalmente tienen que poseer las condiciones que el Mayor. (176-177)

[Sin documentación lexicográfica; cf. DA: 'Gu. Referido a una persona, presa, que sufre prisión. euf.' Parece más bien un parónimo con intención humorística basado sobre presidiario o preso.]

44. Presidente de Golpes. Es el preso bajo cuyas órdenes están todos los golpes. (177)

[Sin documentación lexicográfica]

45. Los presos, en lo general, son muy reservados y muy hombres, como ellos dicen, [...]. (182)

[Santamaría 2000 [1959]: 'SER MUY HOMBRE, o, simplemente, SER HOMBRE. Ser valiente. El sustantivo adquiere calidad de epíteto o adjetivo y resume la cualidad fundamental de varonía, de masculinidad'; DEM: 'Ser muy hombre. Ser, una persona del sexo masculino, fuerte y valiente']

\subsubsection{Variación formal}

La variación formal o paronimia tiene aquí un solo representante, tostador, una variante de tostón 'moneda de cincuenta centavos', formada tal vez con fines humorísticos.

46. Suele jugarse lotería de cartones, que á veces se les permite, y el preso que hace el gasto y aparece como empresario, saca buen provecho, pues suponiendo que se rife un tostón ó tostador, se reparten cincuenta cartones, de á centavo cada uno, y el agraciado paga á aquél cinco centavos de contribución; jugándose, por consiguiente, cincuenta loterías en una noche, cosa muy fácil, atendiendo al poco tiempo que dura cada juego y á lo temprano que se encierra á la gente, el empresario sacaría un diario de dos pesos cincuenta centavos, cantidad que se duplicaría si se rifara un grande, á dos centavos cartón. (208-209)

[Ramos i Duarte 1895: Tostón 'Moneda de plata que representa el valor cincuenta centavos de un peso'; Santamaría 2000 [1959]: Tostón 'Moneda de plata, de a cuatro reales, en el antiguo sistema monetario; de cincuenta centavos, en el actual. Lo mismo en Colombia'; Amor 2014 [1947]: Tostón (cincuenta centavos) 'Michi'] 


\subsubsection{Unidades fraseológicas}

Las unidades fraseológicas no son muchas y son todas locuciones. La mayoría, siete en concreto, son nominales: cabo de bomberos, carro fúnebre, baño de los cachuchas, baño de los chilapeños, pito mayor, pito segundo, presidente de golpes. No estamos seguros del grado de lexicalización de baño de los cachuchas y de baño de los chilapeños, pero como en el texto aparecen entrecomilladas, puede que se trate de locuciones ya lexicalizadas. Locuciones verbales son tres: ser muy hombre, salir a patinar y hacer viaje. Para su documentación textual y lexicográfica, véase supra.

\subsection{VoCES DE PROCEDENCIA OSCURA}

Al final del apartado vamos a presentar un grupo de voces que por falta de más información tenemos que denominar 'de procedencia oscura'. Con mucha probabilidad serán patrimoniales, aunque tal vez no todas. Camonina, chiquito y viejo pertenecen al léxico del juego de cartas que es de tradición hispana y, en principio, patrimonial, aunque puede haber excepciones, como sería el caso de zapote 'trampa' documentado en El Periquillo Sarniento (Buzek 2017). *Pantofacia 'comida' parece seguir el modelo de pseudocultismos habituales en la germanía áurea, mientras que *tuje 'sarape' probablemente será un indigenismo. Algunas de las voces están relativamente bien documentadas en fuentes lexicográficas, mientras que para otras no tenemos ninguna información. En el caso de cachifarro no conocemos el significado y ni siquiera podemos deducirlo del contexto, puesto que la imagen es ilegible. Es el uso de la cursiva que nos dice que según el autor la voz pertenecería al argot carcelario. Las voces *gamuza 'pan', * pitoche 'seis centavos', *sura 'peseta' y *tonedo 'atole' son también oscuras y de momento no tenemos más información sobre su procedencia.

47. [ilegible] cachifarros, como aquí [ilegible] (184)

[Sin documentación lexicográfica]

48. Se sentaba entre una rueda de hombres un preso, que se intitulaba el coime, provisto de un naipe y de diez ó veinte pesos en moneda menuda; echaba el albur, y si la apuesta la perdía el monte, el punto pagaba un real por un peso; por un tostón medio, etc., etc., entendiéndose que esa contribución era, no sólo por albur seco, sino en cada una de las diversas fases que dicho juego tiene, como viejo, camonina, tecolote, chiquito, etc., etc. (210) 
[Santamaría 2000 [1959]: Camonina. 'Apuesta que se hace en el juego del monte, con una de las figuras del albur, pero señalando el palo. Habiendo, por ejemplo, sota y as, se apuesta a la sota o al as que vengan primero, de determinado palo que se elija'; chiquito y viejo no cuentan con documentación lexicográfica]

49. A estos alimentos les llaman los presos pantofacia, y el establecimiento caridad, (y este nombre está bien puesto, porque no se gana por el trabajo), [...]. (127-128)

[Sin documentación lexicográfica]

50. Cuando los presos no tenían dinero, el coime prestaba por una camisa, ó lima, una peseta ó sura; por un zarape, ó tuje, en buen estado, un tostón, ó tostador: y si era enteramente nuevo, un grande, y todo á fuerza de súplicas, resultando, que á las dos ó tres de la mañana y á veces hasta el amanecer, que se levantaba el juego, se encontraba el coime rodeado de un montón de ropa y de una porción de hombres enteramente encuerados. (210)

[Amor 2014 [1947]: Peseta (Veinticinco centavos) 'Sura'; Aguilar 1941: 'Peseta', cf. Surata 'Peseta'; Chabat 1964: 'Veinte y cinco centavos, peseta', $c f$. Sura de varos 'Veinte y cinco pesos' y Surata 'Veinte y cinco centavos, peseta'; Colín 1997 [1987]: 'Moneda de veinticinco centavos']

[Aguilar 1941: Tule 'Zarape'; Chabat 1964: Tuje 'Sarape, cobija' y Tule 'Sarape, cobija'; Colín 1997 [1987]: 'Manta, cobija, sarape']

51. En la mañana á las seis en verano, y á las siete en invierno, una bombilla de atole ó tonedo, y un pambaso, que llaman gamuza ó manrro. (127)

[Ambas sin documentación lexicográfica]

52. Un cigarro de mariguana vale hasta un pitoche (seis centavos). (182) [Aguilar 1941: 'Medio'; Colín 1997 [1987]: Pitoche (medio) 'Un poco'; tal vez por metáfora - 'de escaso valor'; cf. DA: ni pitoche. 'Cu. Absolutamente nada. pop.'; DLE: un pito ‘coloq. Muy poco o nada']

\subsection{VOCES INDOCUMENTADAS EN FUENTES LEXICOGRÁFICAS}

Para más de la mitad de las voces, son 29 en concreto, que según el contexto de la novela pertenecerían al argot carcelario de la época, no hemos encontrado ninguna documentación lexicográfica de control. Aunque es verdad que la documentación lexicográfica no garantiza la existencia real 
de una palabra (Buzek 2010), con mayor número de fuentes de información siempre podemos ofrecer estudios mejor fundamentados. Sin embargo, tenemos a su vez en la memoria la afirmación de Lara (1992) de que las voces jergales casi siempre han sido recolectadas por personas ajenas a los grupos marginados, por lo que sus competencias lingüísticas habrá que tomarlas con cierta reserva.

Las voces ya han aparecido más arriba en su contexto, pero por motivos de coherencia volvemos a resumirlas aquí. Son las siguientes: barrendero; basurero; bicicleta; cabo; cabo de bomberos; cachifarro; calificado; calificar; camonina; carro fúnebre; chiquito; cumplido; destino; *gamuza; gatero; granito; mayor; *pantofacia; salir a patinar; pito; pito mayor; pito segundo; presidente; presidente de golpes; *tecolote 1; *tonedo; *toro; hacer viaje; y viejo.

\subsection{Clasificación temática}

Como el argot carcelario es un sociolecto, una buena parte de su vocabulario recoge términos que reflejan la realidad diaria de la vida penitenciaria: tipos, ocupaciones y jerarquías entre los presos; objetos e instalaciones en la cárcel; o la administración:

- Tipos de presos y sus ocupaciones: barrendero; basurero; cabo 'preso vigilante'; cabo de bomberos 'preso responsable por el orden y la limpieza'; cachucha 'preso distinguido'; chilapeño 'preso ordinario'; cumplido 'preso que ha cumplido la sentencia'; galero 'guardián de celda'; gatero 'preso que sirve a otro'; golpe 'preso que repite las órdenes dadas'; mayor 'preso vigilante'; mula 'preso homosexual'; nagual 'ratero'; salir a patinar 'barrer los espacios públicos fuera de la cárcel'; pito 'cabo de limpieza'; pito mayor 'preso que distribuye la comida'; pito segundo 'preso vigilante'; presidente 'preso vigilante'; presidente de golpes 'preso que dirige a los golpes'; ranchero 'preso que lleva la comida';

- Objetos e instalaciones en la cárcel: bicicleta 'cubo de basura'; carro fúnebre 'vagón que conduce a los detenidos al jurado'; baño de los chilapeños 'baño de los presos ordinarios'; baño de los cachuchas 'baño de los presos distinguidos';

- Administración de la cárcel: calificación 'sentencia provisional'; calificar 'sentenciar provisionalmente'; destino 'lugar donde se cumple la condena'; partida 'registro'; 
Otros ámbitos relacionados con la vida diaria en la cárcel serían la comida y la bebida, el juego y el dinero ("palanca de Arquímedes", como escribe don Celso en una de sus cartas, en la p. 171):

- Comida y bebida: brisa 'carne'; caridad 'comida de la cárcel'; gamuza 'pan'; granito 'arroz aguado'; manrro 'pan'; pantofacia 'comida de la cárcel'; parral 'frijol'; tonedo 'atole'; toro 'carne';

- Juego: camonina, chiquito, tecolote y viejo 'ciertas fases del juego de La Caja';

- Dinero: grande 'peso'; gratificación 'recompensa monetaria'; papel 'billete de banco'; pitoche 'seis centavos'; sura 'peseta'; tostador 'moneda de cincuenta centavos';

Otros campos temáticos son mucho menos representativos y comprenden aquí más bien casos sueltos, como el léxico de fumar (frajo 'cigarrillo'), la vestimenta (lima 'camisa', tuje 'sarape') o cualidades personales (ser muy hombre 'ser muy valiente').

No encontramos en la novela términos relacionados con las actividades delictivas, los tipos de armas, etc. La única excepción sería hacer viaje 'robar', pero este aparece en un pasaje que aunque se ubica en un ambiente marginal, no se desarrolla en la cárcel.

\section{CONCLUSIÓN}

El corpus estudiado en este trabajo se puede considerar como demasiado pequeño y poco representativo, pero si lo ponemos en relación con otros estudios de hablas marginales, podemos observar unas tendencias generales que sintonizan bastante bien con estudios de similar índole. En primer lugar, se confirma que el argot mexicano guarda relaciones de parentesco lejano con el argot español (tanto con el de la época colonial, como con el de sus tiempos), pero posee a la vez varios rasgos que lo identifican como propiamente mexicano. Por una parte, se trata de frutos del contacto con las lenguas indígenas, aunque no ha sido muy intenso porque el argot ha sido siempre urbano y solían prevalecer en él tendencias de evolución patrimoniales (Buzek 2017). Las tendencias patrimoniales se notan no solamente en la lexicogénesis, sino también en los cambios de significado que, por una parte, sintonizan con otros argots hispánicos y, por la otra siguen las tendencias propias del español mexicano popular. 


\section{REFERENCIAS BIBLIOGRÁFICAS}

Adamou, Evangelia. 2013. Replicating Spanish estar in Mexican Romani. Linguistics 51 (6): 1075-1105.

Aguilar, José Raúl. 1941. Los métodos criminales en México. México: Ediciones Lux.

Alonso Hernández, José Luis. 1979. El lenguaje de los maleantes españoles de los siglos XVI y XVII: la germanía (Introducción al léxico del marginalismo). Salamanca: Universidad de Salamanca.

1990. Notas sobre un lenguaje que nunca existió: la jerigonza. Bulletin Hispanique $92(1): 29-44$.

Amor, Ricardo. 2014 [1947]. Diccionario del hampa. Monterrey: Universidad Autónoma de Nuevo León.

[DA]: Asociación de Academias de la Lengua Española. 2010. Diccionario de Americanismos. Madrid: Santillana.

Barriga Villanueva, Rebeca y Pedro Martín Butragueño (dirs). 2010. Historia sociolingüística de México. 2 tomos. México: El Colegio de México, Centro de Estudios Lingüísticos y Literarios.

2014. Historia sociolingüística de México. Tomo 3. México: El Colegio de México, Centro de Estudios Lingüísticos y Literarios.

BuzeK, Ivo. 2010. En torno a un fantasma académico: chislama 'muchacha'. En Daniel Vázquez e Ivo Buzek (eds.), Encuentro de Hispanistas (Brno, 9.-10. ř́jina 2009), pp. 231-241. Brno: Masarykova univerzita.

2014. El tratamiento del léxico de origen gitano en el Diccionario de americanismos de la Asociación de Academias de la Lengua Española. Káñina. Revista de Artes y Letras de la Universidad de Costa Rica XXXVIII (Especial): 19-33.

2015. Diccionario de mejicanismos de Féliz Ramos i Duarte (1895): fuente para la historia del léxico de origen gitano en el español mexicano. Revista Internacional de Lingüística Iberoamericana 26: 125-144.

2017. El léxico de las clases bajas en El Periquillo Sarniento. En Elena Carpi y Rosa M. García Jiménez (eds.). Herencia e innovación en el español del siglo XIX, pp. 45-74.

2018. El léxico carcelario mexicano durante el porfiriato y su lexicografía oculta: un estudio de caso. Boletín de Filología 53 (1): 35-61.

Buzek, Ivo y Katarína Gazdíková. 2017. El léxico carcelario en el Diccionario de mejicanismos de Féliz Ramos i Duarte. Hesperia. Anuario de Filología Hispánica XX (1): 99-109.

Buzek, Ivo y Monika ŠInková (eds.). 2015a. Dossier thématique: "Una cercana diacronía opaca". Estudios sobre el español del siglo XIX (parte primera). Études romanes de Brno 36 (1).

2015b. Dossier thématique: "Una cercana diacronía opaca". Estudios sobre el español del siglo XIX (parte segunda). Études romanes de Brno 36 (2).

Carpi, Elena y Rosa M. García Jiménez (eds.). 2017. Herencia e innovación en el español del siglo XIX. Pisa: Pisa University Press.

Chabat, Carlos G. 1964. Diccionario de caló: el lenguaje del hampa en México. México: F. Méndez Oteo, Librería de Medicina.

Chamorro, María InÉs. 2002. Tesoro de villanos: lengua de jacarandina: rufos, mandiles, galloferos, viltrotonas, zurrapas, carcaveras, murcios, floraineros y otras gentes de la carda. Barcelona: Herder.

Colín SÁnchez, Guillermo. 1997 [1987]. Así habla la delincuencia. México: Porrúa.

Company Company, Concepción (dir.). 2010. Diccionario de mexicanismos. México: Academia Mexicana de la Lengua. 
Davis, JACK Emory. 1956. Estudio lexicográfico de El Periquillo Sarniento. Tesis doctoral. Tulane University.

Franco, J. L. 2014 [194?]. El Canerousse. Monterrey: Universidad Autónoma de Nuevo León.

García Frazier, Elena. 2006. Préstamos del náhuatl al español mexicano. Hesperia. Anuario de Filología Hispánica IX: 75-86.

García González, Francisco. 1894. La Chaquira (Belén por dentro). México: Imprenta "Reina Regente".

García Godoy, María Teresa. 1998. Las Cortes de Cádiz y América. El primer vocabulario liberal español y mejicano (1810-1814). Sevilla: Servicio de Publicaciones de la Diputación.

García ICAZBalceta, Joaquín. 1899. Vocabulario de mexicanismos comprobado con ejemplos y comparado con los de otros países hispano-americanos. México: Tip. y Lit. "La Europea".

GARZA, JAMES Alex. 2007. The imagined underworld: sex, crime, and vice in porfirian Mexico City. Lincoln-London: University of Nebraska Press.

Hernández Alonso, César y Beatriz Sanz Alonso. 2002. Diccionario de germanía. Madrid: Gredos.

Hernández Martínez, Laura. 1999. El argot de los jóvenes. Jóvenes. Revista de Estudios sobre la Juventud 8: 96-107.

2002. De lenguajes juveniles urbanos. La formación de conceptos en caló. En Alfredo Nateras (comp.), Jóvenes, culturas e identidades urbanas, pp. 61-73. México: Universidad Autónoma Metropolitana - Iztapalapa.

2004. A propósito de la violencia del argot. Razón y Palabra 39 [en línea]. Disponible en: http://www.razonypalabra.org.mx/anteriores/n39/lhernandez.html [20/5/2018].

Lakoff, George y Mark Johnson. 2003 [1980]. Metaphors we live by. Chicago: University of Chicago Press.

Lara, Luis Fernando. 1992. El caló revisitado. En Elizabeth Luna Traill (ed.). Scripta Philologica in Honorem Juan M. Lope Blanch a los 40 años de docencia en la UNAMy a los 65 años de vida. Lingüística española e iberoamericana, tomo 2, pp. 567-592. México: Universidad Nacional Autónoma de México, Instituto de Investigaciones Filológicas.

[DEM]: Lara, Luis Fernando. (dir.) 2010. Diccionario del español de México. 2 tomos. México: El Colegio de México, Centro de Estudios Lingüísticos y Literarios.

Lope Blanch, JuAn M. 1965. Influencia de las lenguas indígenas en el léxico del español hablado en México. Anuario de Letras 5: 395-402.

1969. El léxico indígena en el español de México. México: Colegio de México.

Martínez, Olalla, Neus Vila Rubio, Luz Stella Castañeda y José Ignacio Henao. 2012. Formación e incorporación léxica en el argot español y en el parlache. En Neus Vila Rubio y Luz Stella Castañeda Naranjo (eds.). El argot entre España y Colombia. Estudios léxicos y gramáticos, pp. 15-55. Lleida: Edicions de la Universitat de Lleida.

Melis, Chantal y Marcela Flores (eds.). 2015. El siglo XIX. Inicio de la tercera etapa evolutiva del español. México: Universidad Nacional Autónoma de México.

OesterReicher, Wulf. 2004. Textos entre inmediatez y distancia comunicativas. El problema de lo hablado escrito en el Siglo de Oro. En Rafael Cano Aguilar (ed.). Historia de la lengua española, pp. 729-770. Barcelona: Ariel.

Ramírez Luengo, José Luis (ed.). 2012. Por sendas ignoradas. Estudios sobre el español del siglo XIX. Lugo: Axac.

Ramos i Duarte, Féliz.1895. Diccionario de mejicanismos. Colección de locuciones i frases viciosas, con sus correspondientes críticas i correcciones fundadas en autoridades de la lengua; máximas, refranes, provincialismos y retoques populares de todos los Estados de la República Mejicana. Méjico: Imprenta de Eduardo Dublan. 
[DLE]: Real Academia Española. 2014. Diccionario de la Lengua Española. 23a ed. Madrid: Espasa.

Salillas, Rafael. 1896. El delincuente español. El lenguaje. Madrid: Librería de Victoriano Suárez.

Sanmartín SÁez, Julia. 1998. Lenguaje y cultura marginal: el argot de la delincuencia. València: Universitat de València.

2006. Diccionario de argot. Madrid: Espasa.

Santamaría, Francisco J. 2000 [1959]. Diccionario de mejicanismos. Méjico: Porrúa.

Trejo, Arnulfo. 1961. El argot como medio de expresión en la prosa mexicana. Anuario de Letras 1: 173-179.

Universidad Nacional Autónoma de México y Biblioteca Nacional de México. Hemeroteca Nacional Digital de México [en línea]. Disponible en http://www.hndm.unam.mx/index. php/es/ [28/1/2018].

Zamorano Aguilar, Alfonso (ed.). 2012. Reflexión lingüistica y lengua en la España del XIX. Marcos, panoramas y nuevas aportaciones. München: LINCOM. 